CAPALDI, E. J. A sequential hypothesis of instrumental learning. In Spence, K. W. and Spence, I. T. (Eds.), The psychology of learning and motivation, Vol. 1 . New York: Academic Press, 1967.

ELSTAD, PATRICIA. Shifts in per cent reinforcement and resistance to extinction in instrumental reward conditioning. Ph.D. dissertation, University of lowa, 1966.

MANDELL, E. "Resistance to extinction" of a pursuit-rotor tracking response as a function of prior schedule of knowledge of results. Doctoral dissertation, University of South Carolina, 1969

MAY, J. Effects of shifts in experimenter-determined "knowledge of results" and an analogue of resistance to extinction of a perceptual-motor response. Master's thesis, University of South Carolina 1968.
SPENCE, K. W. Behavior theory and learning. Englewood Cliffs, N.J.: Prentice-Hall, 1960.

\section{NOTE}

1. The expression "knowledge of results" (KR), as used in this paper, is more correctly referred to as "augmented knowledge of results." The pursuit-rotor task inherently provides $S$ with considerable knowledge of his performance, since $S$ could directly observe visually the contact of the stylus with the target as well as hear the closure of a relay whenever the stylus made contact with the target. Thus, informing $S$ of his time-on-target only "augmented" this KR. Nevertheless, for simplicity of description, the $E$ 's statement to $S$ of his time-on-target is referred to as "KR" for the purpose of this paper.

\title{
The reinforcing value of secret information 1
}

\author{
ROBERT FRANK WEISS and JOYCE \\ JETTINGHOFF WEISS, University of \\ Oklahoma, Norman, Okla. 73069
}

Information was found to effectively reinforce an opinion response, and this result could be unambiguously attributed to reinforcement rather than to some other facilitating effect of information. Secret information and freely communicable information did not differ in their reinforcing effectiveness ( $N=90)$.

A variety of studies indicate that information may be used as a reinforcer of instrumental responses. Such studies show that response strength depends upon informational reinforcement in human instrumental conditioning (Jones, 1966), verbal discrimination learning (Spence, 1964), conditioning of attitudes (Weiss, 1968), perceptual-motor performance (Brown, 1949), and even in the secondary reinforcement of white rats (Egger \& Miller, 1962) or fixed-ratio performance of pigeons (Hendry, 1969).

Brock's (1968) commodity theory of the transmission and value of information proposes that recipients of information value secret information more highly than they do information that is freely communicable. Brock's research on the value of information and the research on informational reinforcement may be combined to yield the prediction that secret information should be a stronger reinforcer than freely communicable information, because the secret information is more valued.

\section{SUBJECTS AND DESIGN}

The Ss were 90 female undergraduates. There were two experimental groups and three control groups, with $18 \mathrm{Ss}$ in each group. Both experimental groups received the same information as reinforcement, one with secrecy instructions and one without. All three control groups made the response but were not reinforced. There was a no-information control group. Two other control groups were included against the possibility that the secrecy instructions or highly interesting information could facilitate performance by some means other than reinforcing that performance. In these two (one secret, one open) control groups, the Ss were exposed to the information, but the information was not used as a reinforcer. The information preceded, rather than followed, the instrumental response. Since presentation of the information was not contingent upon the $S$ 's making the instrumental response, any information effects in these control groups would not be due to reinforcement of the instrumental response.

\section{REINFORCERS}

A boundary condition of Brock's commodity theory states that "when prospective recipients are uninterested in particular information, commodity propositions are inapplicable [Brock, 1968, p. 2711." It was, therefore, necessary to develop an informational reinforcer that met this boundary condition unambiguously and that could plausibly be made secret. The reinforcer chosen was information concerning (favorable) personality traits ostensibly measured by a psychological test. Previous experiences with Ss, and informal interviews following this experiment, indicate that Ss are very much interested in receiving information about their personalities.

The information was made secret for the secret groups by telling them that the information was highly confidential and that: (1) disclosure could ruin future research because "if a person reads into the analyzer knowing which traits are being measured, his preconceived ideas will spoil the test"; and (2) only Ss who scored in the top $20 \%$ on a paper-and-pencil "discretion scale" were being trusted with the results of their tests. Moreover, all secret Ss were required to sign the statement, "I hereby swear (affirm) that I will maintain in confidence, and will in no way disclose any scores or results of this research," and this statement was signed in witness by the $E$. This procedure combines 
several of Brock's criteria, including those which state that information will increase in value "the greater the restraints set by the communicator on further transmission," the greater the "amount of accompanying reasons opposing disclosure," and, by dint of the discretion scale, "as the perceived number of co-recipients, relative to the total number of potential recipients, declines [Brock, 1968, p. 248, 250]."

\section{TRAINING PROCEDURES}

Ideally, the effects of the secret and open informational reinforcers should be studied by using them to reinforce some simple, well researched motor response, known to exemplify conditioning principles. However, the necessity of meeting the conditions of commodity theory by having both clearly interesting information and an effective and plausible secrecy manipulation had to be the paramount consideration. It is difficult to imagine what interesting secret information could plausibly be provided as reinforcement for bar pressing, but the informational reinforcers described above could be plausibly presented in the course of an attitude-conditioning experiment. Informational reinforcement has been used successfully in previous attitude-conditioning experiments (e.g., Scott, 1957; Weiss, 1968). The experiment was represented to the Ss as a study of "speech patterns, personality, and decision making." Speech patterns and personality were ostensibly assessed by instructing $S$ to read four short passages into the microphone of a very impressive-looking "electronic speech analyzer." This speech analyzer provided the personality scores used as reinforcement. One of the passages read was a persuasive communication, and the response to be learned was the opinion stated in the communication. Thus, the person first made the opinion response to be learned and then received reinforcing information about his personality. In order to study "conditioning" rather than "habit reversal," the persuasive communication was directed at a fictitious opinion topic, on which $97 \%$ of a sample of similar Ss had no initial opinion ("The Bonda fossil was a bird").

Details of the training procedure included the following. The reinforcing information on the single training trial was: "You score very high on the self-confidence dimension. Your score is in the 96 th percentile... you are not a hysterical person because your hysteria score falls in the 10 th percentile, meaning $90 \%$ of the people tested scored higher than you." In order to minimize suspicion over the favorability and extremity of the personality scores, the training trial was preceded by a dummy trial ending with the information: "You scored in the 75th percentile on pretentiousness; the tendency to impress others with a false front ... your score on the restlessness scale falls in the 53rd percentile." All personality scores were systematically varied $\pm 2 \%$ from $S$ to $S$ in order to minimize suspicion in the $S$ pool. Secret Ss were reminded of the secrecy immediately before the information was presented; delay of reinforcement was held constant across secret vs nonsecret groups by an interval timer in the "speech analyzer," which always delivered the scores to the E $20 \mathrm{sec}$ after the reading.

The contingent vs noncontingent presentation of the information was arranged in the following manner. A trial consisted of reading two passages, of which the persuasive communication was the second. The Ss were told that each pair of passages consisted of one standard passage that could be scored now and one new passage on which research had just begun and therefore could not yet be scored. Scores were reported immediately after the "standard" passage was read. The persuasive communication was represented to the reinforced $\mathrm{Ss}$ as the standard passage, so that they received their personality scores immediately after reading the persuasive communication. Conversely, the first passage was represented to the noncontingentinformation controls as the standard passage, so that they received their scores after the first passage and before reading the persuasive communication.

\section{TESTING PROCEDURE}

Following training, a latency measure of opinion-response strength was obtained. A statement of the opinion (preceded by seven buffers) was shown behind a transparent mirror-glass screen, and $S$ signified his agreement (if he agreed) by pressing a lever. When an opinion statement appeared, an electric timer automatically began to measure latency of agreement (to .01 sec), stopping automatically when the lever was pressed (speed $=1 /$ latency). The timing equipment was located in a separate control room and was not visible or audible to the Ss, who did not know they were being timed. If an $S$ did not respond within $30 \mathrm{sec}$, his speed of agreement was considered to be zero. Ss who did not agree did not move the lever. The testing procedure was represented to the $S$ s as a decision-making test.

\section{RESULTS AND DISCUSSION}

The mean agreement speeds of the no-information control group (.149) and the noncontingent-information controls $(.188)$ did not differ significantly $(t=.86)$. The personality information did reinforce the opinion response: The mean speed of the two reinforced groups (.261) was significantly faster than that of the no-information controls $(t=1.99, \mathrm{df}=52$, $\mathrm{p}<.03$, one tail) and the noncontingent-information controls $(\mathrm{t}=1.66, \mathrm{df}=70, \mathrm{p}=.055$, one tail). The secret information was not, however, any more effective a reinforcer than the freely communicable information, with the slight nonsignificant difference in the means actually being in the opposite direction from that predicted (secret $=.255$, open $=.267$ ). The results thus offer no support for the writers' integration of reinforcement principles with commodity-theory principles. It is important to note that this experiment does not test commodity theory itself but, rather, a novel extension of it; commodity theory (Brock, 1968) does not itself treat of the reinforcing function of information. The superiority of the reinforced groups over the controls does, however, offer novel support for informational reinforcement principles and especially for the application of these principles to opinion-change research. In particular, the presence of the noncontingent control groups in the experiment permits the results to be clearly attributed to reinforcement rather than to some other facilitating effect of information.

\section{REFERENCES}

BROCK, T. C. Implications of commodity theory for value change. In A. G. Greenwald, T. C. Brock, and T. M. Ostrom (Eds.), Psychological foundations of attitudes New York: Academic Press, 1968. Pp. 243-276.

BROWN, J. S. A proposed program of research on psychological feedback (knowledge of results) in the performance of psychomotor tasks. In: Research planning conference on perceptual and motor skills, USAF Human Resources Center Conference Report No. 49-2, 1949. Pp. 81-87.

EGGER, M. D., \& MILLER, N. E. Secondary reinforcement in rats as a function of information value and reliability of the stimulus. Journal of Experimental Psychology, 1962, 64, 97-104.

HENDRY, D. P. Reinforcing value of information: Fixed-ratio schedules. In D. P. Hendry (Ed.), Conditioned reinforcement. Homewood, Ill.: Dorsey, 1969. Pp. 300-341.

JONES, A. Information deprivation in humans. In B. A. Maher (Ed.), Progress in experimental personality research. Vol. 3. New York: Academic Press, 1966. Pp. 241-307.

SCOTT, W. A. Attitude change through reward of verbal behavior. Journal of Abnormal \& Social Psychology, 1957, 55, 72-75.

SPENCE, J. T. Verbal discrimination performance under different verbal reinforcement combinations. Journal of Experimental Psychology, 1964, 67, 195-197.

WEISS, R. F. An extension of Hullian learning theory to persuasive communication. In A. G. Greenwald, T. C. Brock, and T. M. Ostrom (Eds.), Psychological foundations of attitudes. New York: Academic Press, 1968. Pp. 109-146.

NOTE

1. Research supported by National Institute of Mental Health Grant MH-12402. 